\title{
ERRATUM
}

\section{Giving catalysis the edge}

Daniel E. Resasco

Nature Nanotechnology 3, 708-709 (2008); published online: 5 December 2008; corrected after print: 27 January 2009.

In the version of this News \& Views originally published, the structure shown in Fig. 1a was incorrect and should have appeared as shown below. This has been corrected in the HTML and PDF versions.

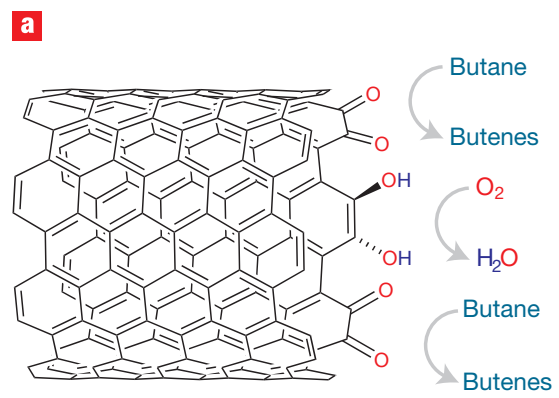

